\title{
Histopathological Study and Pattern of Lymph Node Involvement in Carcinoma Esophagus: A Tertiary Care Centre Experience from Northern India
}

\author{
Sanjeev Parshad ${ }^{1}$, Sushil Kumar ${ }^{2}$, Ravinder Kumar³, Kapil Kadian ${ }^{3}$ \\ ${ }^{1}$ Professor, Department of General Surgery, ${ }^{2}$ Assistant Professor, Department of Surgical Oncology, \\ ${ }^{3}$ Senior Resident, Department of General Surgery, Pt B D Sharma PGIMS Rohtak
}

\begin{abstract}
Background: Esophageal cancer remains one of the deadliest cancers with an overall 5-year survival rate estimated to be less than $18 \%$. Squamous cell carcinoma of the esophagus is the predominant histology in the cervical esophagus and upper and middle thirds of the thoracic esophagus, whereas adenocarcinoma predominates in the distal esophagus. Lymph node involvement and the number of lymph node metastases are important prognostic factors
\end{abstract}

Materials and Methods: 30 patients of mid and lower thoracic esophageal carcinoma treated between 2008 to 2014 were studied retrospectively. Histopathological profiles were analysed mainly in terms of pattern of lymph node involvement.

Results: 26 cases were squamous cell carcinoma and 3 were adenocarcinoma while 1 case was pathological complete response after neoadjuvant treatment. 22/30 were moderately differentiated. 24/30 had lymph node involvement where T3N1 was the commonest stage as 50\% had achieved this stage. Mediastinal group of lymph nodes were involved in 23 cases upper abdominal lymph nodes were involved only in 1 case while cervical lymph nodes were not involved in any case. Among mediastinal group paraesophageal, paratracheal lymph node involvement was the commonest followed by subcarinal and recurrent laryngeal group of lymph nodes.

Conclusion: Squamous cell carcinoma is still the commonest variety prevailing in this region. Majority of the cases present in advanced stage with lymph node involvement. Mediastinal group of lymph nodes are involved in majority of the cases hence precise clearance of this group is of utmost importance to prevent local recurrence and prolonged survival.

Keywords: Carcinoma esophagus, squamous cell carcinoma, Mediastinal lymph nodes

\section{Introduction}

Esophageal cancer remains one of the deadliest cancers with an overall 5-year survival rate estimated

\section{Corresponding Author:}

Dr Sushil Kumar

Department of Surgical Oncology

Pt B D Sharma PGIMS Rohtak, Haryana

Email: sushilkumar455@rediffmail.com

contact no: 9006411158 to be less than $18 \%{ }^{1}$. Tobacco and alcohol use are considered the major contributing factors in the development of esophageal cancer worldwide. Histologically, in the United States esophageal adenocarcinoma is the fastest-growing subtype, surpassing the incidence of esophageal squamous cell carcinoma (SCC), in contrast to worldwide incidence where SCC still predominates ${ }^{2,3}$. SCC of the esophagus is the predominant histology in 
the cervical esophagus and upper and middle thirds (above the pulmonary vein) of the thoracic esophagus, whereas adenocarcinoma predominates in the distal esophagus. Tumors of the cervical and upper third of the thoracic esophagus drain to cervical and superior mediastinal lymph nodes. Tumors of the middle third of the esophagus drain both cephalad and caudad with lymph nodes at risk in the paratracheal, hilar, subcarinal, periesophageal, and pericardial nodal basins. Lesions in the distal esophagus primarily drain to lymph nodes in the lower mediastinum and celiac axis region. Because of the extensive lymphatic network within the wall of the esophagus, skip metastases for upper third lesions have been noted in celiac axis nodal basins, and likewise, cervical lymph node metastases have been noted in as many as $30 \%$ of patients with distal esophageal lesions.

Lymph node involvement and the number oflymph node metastases are important prognostic factors and the pattern of lymph node metastases is very complex.
Considering this fact, this histopathological study was carried out to assess the pattern of lymph node metastasis in patients of esophageal carcinoma in our population.

\section{Materials and Methods}

This retrospective study was carried out in the Department of Surgical Oncology at PGIMS Rohtak where histopathological examination reports of 30 patients of carcinoma esophagus operated between 2008 to 2014 were analysed using Microsoft excel sheet. All the cases were either mid thoracic or lower thoracic esophageal carcinoma and the surgery done was Transthoracic esophagecomy.

\section{Results}

Out of 30 cases 19 were male and 11 were female. Male to female ratio was 1.72:1. Maximum number of patients were of the $6^{\text {th }}$ decade of life (13 out of 30 ) with 29 years being the youngest and 77 years the

oldest.

Table 1 - Age distribution of patients

\begin{tabular}{|c|c|}
\hline Age group (in years) & No of patients(n) \\
\hline $21-30$ & 1 \\
\hline $31-40$ & 2 \\
\hline $41-50$ & 7 \\
\hline $51-60$ & 13 \\
\hline $61-70$ & 5 \\
\hline $71-80$ & 2 \\
\hline
\end{tabular}

26/30 cases were squamous cell carcinoma and only 3 were adenocarcinoma while no tumour was identified in 1 case due to pathological complete response after neoadjuvant therapy. 
Table 2 - Histology of patients

\begin{tabular}{|c|c|}
\hline Histology & No of cases (n) \\
\hline Squamous cell carcinoma & 26 \\
\hline Adenocarcinoma & 3 \\
\hline Pathological complete response & 1 \\
\hline
\end{tabular}

With available information on histologic grade , 22/30 were moderately differentiated, 1 was well differentiated and 1 was undifferentiated.

Table 3 - Histologic grade

\begin{tabular}{|c|c|}
\hline Histologic Grade & No of cases (n) \\
\hline Well deifferentiated & 1 \\
\hline Moderately differentiated & 22 \\
\hline Undifferentiated & 6 \\
\hline Not documented & 6 \\
\hline
\end{tabular}

$80 \%(24 / 30)$ of the patients had lesion involving through all the layers of the esophagus. Average number of lymph nodes harvested were 14.3 per patient and ranged from 0 to $30.80 \%(24 / 30)$ of the cases had one or more lymph node involvement. Pathological T3N1 was the commonest stage found in 14 out of 30 cases.

Table 4 - Pathological TNM staging

\begin{tabular}{|c|c|}
\hline Pathological stage & No of cases (n) \\
\hline T0N0M0(Pathologicalcomplete response) & 1 \\
\hline T2N0M0 & 2 \\
\hline T2N1M0 & 2 \\
\hline T2N2M0 & 1 \\
\hline T3N0M0 & 3 \\
\hline T3N1M0 & 14 \\
\hline T3N2M0 & 4 \\
\hline T3N3M0 & 3 \\
\hline
\end{tabular}

All lymph node involvement were in the mediastinal group and among them paraesophageal/ paratracheal lymph nodes were the commonest followed by sub carinal and recurrent laryngeal group.
Single case was found to involve upper abdominal group i.e lymph nodes around celiac axis while no lymph nodal involvement was found in cervical lymph nodes. 
Table 5 - Pattern of lymph node involvement

\begin{tabular}{|c|c|c|}
\hline \multicolumn{2}{|r|}{ Lymph node group } & No of cases $(n=24)$ \\
\hline & Cervical & 0 \\
\hline & Mediastinal & 23 \\
\hline a) & Periesophageal/ Paratracheal & 15 \\
\hline b) & Subcarinal & 4 \\
\hline c) & Recurrent laryngeal & 4 \\
\hline & bdominal i.e along celiac axis & 1 \\
\hline
\end{tabular}

\section{Discussion}

Esophageal carcinoma is rare in people under 40 years of age, and its rate increases every decade ${ }^{4}$. In our study, age range was $29-77$ years. $66 \%$ were seen in $5^{\text {th }}-6^{\text {th }}$ decade of life which was found in previous studies $^{5,6}$. There is extensive variation in male to female ratio as far as squamous cell esophageal Carcinoma is concerned ${ }^{7,8}$. In our study, the male: female ratio was 1.7:1. The higher percentage of tumor in our male population may be attributed to higher prevalence of smoking and alcohol consumption as compared to females.

Esophageal cancers are histologically classified as SCC or adenocarcinoma9 ${ }^{9}$ SCC is a malignant

epithelial tumorwith squamous cell differentiation, microscopically characterized by keratinocyte-like cells with intercellular bridges and/or keratinization. Adenocarcinoma is a malignant epithelial tumor with glandular differentiation arising predominantly from Barrett esophagus mucosa in the lower third of the esophagus. SCC and adenocarcinoma are assumed to have different biologic behaviors, which might influence treatment choices. SCC seems to

bemoresensitivetochemotherapy, chemoradiation, and radiotherapy than adenocarcinoma, but the long-term outcome of therapy appears to be similar. Adenocarcinoma may be associated with a better long-term prognosis after resection than $\mathrm{SCC}^{10}$. SCC being the commonest histology found worldwide and the same was found in our study which is consistent with the study done by Kotwal et $\mathrm{al}^{11}$.

The tumor grade reflects the histologic aggressiveness of the cancer. It can be an indicator of how quickly a tumor is likely to grow and spread. Cancers that are "well-differentiated" tend to grow and spread at a slower rate than tumors that are "undifferentiated" or "poorly differentiated."In our study $73 \%$ of the cases were moderately differentiated suggestive of tumour of intermediate grade which is different from study done by Come et al ${ }^{12}$.

The depth of tumor invasion is associated with lymph node metastasis and the number of positive lymph nodes. Once the tumor cells have breached the basement membrane of the epithelium, potential metastasis can develop ${ }^{13}$. The cells spread from the mucosal lymphatic ducts to drain into a rich submucosal plexus and can then spread longitudinally through this dense lymphatic network and invade the paraesophageal lymphatic system. The same is observed in present study where lymph node positivity increased from $60 \%$ to $87 \%$ as tumour depth increased 
from $\mathrm{T} 2$ to $\mathrm{T} 3$.

Lymph node status, such as the number of positive nodes and number of fields with lymph node metastasis are among the most important predictors for survival after esophagectomy ${ }^{14,15}$. The current AJCC guidelines do not specify the number of lymph nodes to be removed, but instead suggest that the surgeon resect as many lymph nodes as possible while minimizing morbidity. The present study determined the pattern of lymph node involvement and found that lymph node was involved in $80 \%$ of the cases and mainly belonged to mediastinal group particularly paratracheal and paraesophageal lymph nodes followed by subcarinal and recurrent laryngeal nodes. Involvement of upper abdominal group was rare which is consistent with the study done by Bin et $\mathrm{al}^{16}$. None of the case had cervical lymph nodal metastasiss. These results confirmed the anatomic observations ${ }^{17-19}$ that a long longitudinal extension of lymphatic drainage in the submucosa is connected to the superior mediastinum along the recurrent nerve and paracardial lymphatics. On the basis of our data we believe that Transthoracic esophagectomy should be the choice of surgery even for lower thoracic tumours to carefully resect maximum number of lymph nodes for correct tumor staging and to reduce the local recurrence.

\section{Conclusion}

Squamous cell carcinoma is still the commonest histology prevailing in our population. Majority of the cases present in advanced stage with lymph node involvement. Mediastinal group of lymph nodes are involved in majority of the cases hence precise clearance of this group is of utmost importance to prevent local recurrence and prolonged survival.

\section{Conflict of Interest: No}

\section{Source of Funding: Self}

\section{References}

1. Siegel R, Naishadham D, Jemal A. Cancer statistics, 2012. CA Cancer J Clin. 2012;62:1029.

2. Baquet CR, Commiskey P, Mack K, Meltzer S, Mishra SI. Esophageal cancer epidemiology in blacks and whites: racial and gender disparities in incidence, mortality, survival rates and histology. J Natl Med Assoc. 2005;97:1471-1478.

3. Jemal A, Murray T, Ward E, et al. Cancer statistics, 2005. CA Cancer J Clin. 2005;55:1030 .

4. Turkyilmaz A, Eroglu A, Subasi M, Karaoglanoglu N. Clinicopathological features and prognosis of esophagea cancer in young patients. Is there a difference in outcome? Dis Esophagus 2009;22:211-215.

5. Nafees A Qureshi, Michael T Hallissey, John W; Fielding. Outcome of index upper gastrointestinal endoscopy in patients presenting with dysphagia in a tertiary care hospital - A 10 years review. BMC Gastroenterol. 2007;7:43.

6. Bazaz -Malik G, Lal N; Malignant tumors of the digestive tract. A 25 year study. Indian J Pathol Microbiol. 1989;32(3):179-185.

7. Cambell F, Bogomoletz W V, Williams G T. Tumours of esophagus/stomach. In: D Chistopher, Fletcher M, eds. Diagnostic Histopathology of Tumours 2nd ed. Philadephia: Churchill Livingston; 2003. P.313-68.

8. Atila EROĞLU1, Yener AYDIN1, Bayram ALTUNTAŞ1, Ömer YILMAZ. The increasing incidence of esophageal squamous cell carcinoma in women in Turkey. Turk J Med Sci 2016;46(5):1443-1448.

9. Siewert JR, Katja O. Are squamous and adenocarcinomas of the esophagus the same disease? Semin Radiat Oncol. 2007;17:38-44.

10. Siewert JR, Stein HJ, Feith M, Bruecher BL, Bartels H, Fink U. Histologic tumor type is an 
independent prognostic parameter in esophageal cancer: lessons from more than 1,000 consecutive resections at a single center in the Western world. Ann Surg. 2001;234:360-367.

11. Kotwal S, Gandotra V, Gupta D, Suri J. Histopathological spectrum of carcinoma esophagus: A 5 year retrospective study . Indian journal of pathology and oncology (2017), 3, vol $4: 458-461$.

12. Come J, Castro C,Morais A, Cossa M,Modcoicar P, Tulsidas S, Cunha L, Lobo V, Morais AG, Cotton S, Lunet S, Carrilho C, Santos LL. Clinical and Pathologic Profiles of Esophageal Cancer in Mozambique: A Study of Consecutive Patients Admitted to Maputo Central Hospital. Journal of Global Oncology(2018), vol4

13. Rice TW. Superficial oesophageal carcinoma: is there a need for three-field lymphadenectomy? Lancet. 1999;354:792-4.

14. Shimada H, Okazumi S, Matsubara H, Nabeya Y, Shiratori T, Shimizu T, et al. Impact of the number and extent of positive lymph nodes in 200 patients with thoracic esophageal squamous cell carcinoma after three-field lymph node dissection. World J Surg. 2006;30:1441-9
15. Liu YP, Ma L, Wang SJ, Chen YN, Wu GX, Han M, et al. Prognostic value of lymph node metastases and lymph node ratio in esophageal squamous cell carcinoma. Eur J Surg Oncol. 2010;36:155-9.

16. Bin Li, MD,a,b Haiquan Chen, MD,a,b Jiaqing Xiang, MD,a,b Yawei Zhang, MD,a,b Chenguang Li, MD,a,b Haichuan Hu, MD,a,b and Yang Zhang, MDa. Pattern of lymphatic spread in thoracic esophageal squamous cell carcinoma: A single-institution experience. ( $\mathrm{J}$ Thorac Cardiovasc Surg 2012;144:778-86)

17. Kuge K, Murakami G, Mizobuchi S, Hata Y, Aikou T, Sasaguri S. Submucosal territory of the direct lymphatic drainage system to the thoracic duct in the human esophagus. J Thorac Cardiovasc Surg. 2003;125:1343-9.

18. Mizutani M, Murakami G, Nawata S, Hitrai I, Kimura W. Anatomy of right recurrent nerve node: why does early metastasis of esophageal cancer occur in it? Surg Radiol Anat. 2006;28:333-8.

19. Tachimori Y, Nagai Y, Kanamori N, Hokamura $\mathrm{N}$, Igaki H. Pattern of lymph node metastases of esophageal squamous cell carcinoma based on the anatomical lymphatic drainage system. Dis Esophagus. 2011;24:33-8. 